\title{
Neurohypophyseal Peptide Levels in CSF and Plasma during Passive Avoidance Behavior in Rats
}

\author{
Wim B. J. Mens, ${ }^{1}$ Marion A. H. van Egmond, August A. De Rotte, \\ and TJEeRd B. van Wimersma Greidanus
}

\author{
Rudolf Magnus Institute for Pharmacology, University of Utrecht, Medical Faculty, \\ Vondellaan 6, 3521 GD Utrecht, The Netherlands
}

\begin{abstract}
Levels of vasopressin (AVP), oxytocin (OXT), and neurophysin (NP) in CSF and plasma of rats were determined during acquisition and retention of passive avoidance behavior. None of the levels of neurohypophyseal peptides in CSF were changed either during the adaptation period, or during acquisition or the retention of this behavior. Moreover, no differences were found in hormone levels in CSF of the various groups of rats subjected to different shock intensities during the acquisition trial. The marked differences in individual latencies of nonavoiding rats, and the differences in latencies due to a different shock intensity applied during the learning trial were not reflected by changes in CSF hormone levels. Neither AVP nor NP levels in plasma were affected by the different shock intensities applied, when measured at $20 \mathrm{~min}$ after the learning trial. In contrast, a decrease in plasma OXT levels was observed after application of a shock intensity of $0.25 \mathrm{~mA}$ during the learning trial. During retention of the passive avoidance response plasma levels of AVP, OXT and NP were not different from the levels found in the nonshocked groups. It is suggested that under the conditions used in this study the CSF is apparently not involved in the distribution of neurohypophyseal peptides to their possible sites of behavioral action in the brain.
\end{abstract}

Arginine-8-vasopressin (AVP) and oxytocin (OXT) both modulate memory processes. AVP affects memory processes by facilitating both storage and retrieval of information (Ader and De Wied, 1972; Rigter, Van Riezen, and De Wied, 1974; De Wied, 1976), whereas OXT generally has an opposite effect. This latter neuropeptide may be a naturally occurring amnesic neuropeptide (Bohus, Kovács, and De Wied, 1978a). From the effects of AVP in rats bearing lesions in various limbic structures as well as from the effects of locally applied vasopressin, it was suggested that AVP may act on intact midbrain limbic circuits, including

\footnotetext{
${ }^{1}$ To whom all correspondence should be addressed.
} 
septal, amygdaloid, parafascicular, and hippocampal structures to facilitate the storage and/or retrieval of acquired behavior (Van Wimersma Greidanus, Croiset, Bakker, and Bouman, 1979a).

Intracerebroventricular (icv) administration of minute amounts of AVP facilitate active and passive avoidance behavior (De Wied, 1976), whereas icv application of AVP antiserum immediately after the learning trial induces a marked deficit in retention of a passive avoidance response (Van Wimersma Greidanus and De Wied, 1976; Van Wimersma Greidanus, 1978). However, peripheral injection of one hundred times as much AVP antiserum resulting in a marked decrease in urine AVP levels, did not affect passive avoidance behavior (Van Wimersma Greidanus, Dogterom, and De Wied, 1975).

OXT-administered icv caused an attenuation of retention of a passive avoidance response, whereas administration of OXT antiserum has an opposite effect (Bohus, Urban, Van Wimersma Greidanus, and De Wied, 1978b). These results suggest that centrally released AVP or OXT rather than AVP or OXT secreted into the blood are involved in the behavioral actions of these neuropeptides. This hypothesis is also supported by previous observations that plasma AVP levels of rats submitted to acquisition and retention of passive avoidance behavior were not changed as compared to controls. Only $5 \mathrm{~min}$ after the onset of the retention session of a passive avoidance task a slight but significant elevation of plasma AVP levels was found in animals that displayed a long avoidance latency (Van Wimersma Greidanus, Croiset, Goedemans, and Dogterom, 1979b).

AVP and its associated neurophysin (NP) are synthesized in cell bodies of supraoptic, paraventricular, and suprachiasmatic nuclei of the anterior hypothalamus (Sachs, Fawcett, Takabatake, and Portanova, 1969; Swanson and Cowan, 1975; Vandesande, Dierickx, and De Mey, 1975), whereas OXT and its associated NP are formed in the supraoptic and paraventricular nuclei (Swaab and Pool, 1975; Sofroniew and Weindl, 1978). Morphological evidence points to connections between these neurosecretory cells and the infundibular recess of the third ventricle (Wittkowski, 1968; Goldsmith and Zimmerman, 1975; Sokol, Zimmerman, Sawyer, and Robinson, 1976) and the lateral ventricle (Brownfield and Kozlowski, 1977). From these sites neurohypophyseal principles may be released into the cerebrospinal fluid (CSF) and by this route reach other brain areas where they exert their behavioral effect.

In the present study CSF neurohypophyseal peptide levels during passive behavior were measured, in order to further elucidate the involvement of CSF as a transport medium for these peptides to reach other brain areas where they may act for their behavioral effect. In addition plasma levels of neurohypophyseal peptides have been measured as well. 


\section{MATERIALS AND METHODS}

Male rats of an inbred Wistar strain (Cpb-TNO, Zeist, The Netherlands) weighing 170-180 $\mathrm{g}$ at the start of the experiment were used. The rats were housed in separate cages and maintained ad lib on food and water. The lights in the animal house were on between 5 AM and 7 PM. On each experimental day the rats were transported from the animal house to the experimental room.

In order to collect CSF from freely moving rats, a permanent stainlesssteel cannula was implanted in the cisterna magna of the animals. The cannula used differed from the one described by Bouman and Van Wimersma Greidanus (1979), in that the cannula was not equipped with a special outflow opening and that at $6.5 \mathrm{~mm}$ above the inflow opening a stainless-steel round plate (diameter $2.5 \mathrm{~mm}$ ) was placed at an angle of $45^{\circ}$. The cannula was placed into the cisterna magna in such a way that the stainless-steel plate fitted on the skull of the rat. The advantage of this cannula is that it can be implanted by hand, no special stereotaxic apparatus being necessary, and the operation takes only $10 \mathrm{~min}$. Amounts of 50-100 $\mu$ l of CSF can be collected repeatedly without any sign of disturbing the animal. No replacement of collected CSF took place.

Passive avoidance behavior was studied using a paradigm as described by Ader, Weijnen, and Moleman (1972) with minor modifications (Thompson and De Wied, 1973). This situation uses the innate preference of rats for darkness over light. Animals were trained in a step-through type procedure, which consisted of a dark compartment to which an illuminated platform was attached at the front center. Adaptation to the behavioral situation was performed by placing the animal for $2 \mathrm{~min}$ in the dark compartment. Adaptation was followed by a trial in which the animals were placed on the platform in their initial latencies to enter were measured. Three such trials were given on the second day. After the third trial the animals received an unescapable foot shock (EFS) through the grid floor of the dark compartment (learning trial). The shock intensities applied during this single learning trial were 0.00 (no shock, controls), $0.25,0.50$, and $0.75 \mathrm{~mA}$ for $3 \mathrm{sec}$. Retention of the passive avoidance response was tested $24 \mathrm{hr}$ after the learning trial and the latency to enter the dark compartment was recorded for a maximum observation time of $180 \mathrm{sec}$.

Radioimmunoassays (RIAs)

Oxytocin was determined using a RIA procedure, based on the RIA for AVP. The antibodies were raised in rabbits, using a similar procedure as described by Dogterom, Van Wimersma Greidanus, and De Wied (1978) for AVP. The antiserum used $\left(O_{\text {II }}\right.$ in a final dilution of $\left.1: 20,000\right)$ was highly specific for OXT, the cross-reactivity with AVP was less than $0.3 \%$, and arginine vasotocin (AVT) had approximately $1.5 \%$ cross-reac- 
tivity. The maximal binding capacity amounted to $1.7 \mathrm{ng} / \mu$ l undiluted antiserum. The detection limit of the assay was $2.0 \mathrm{pg} /$ tube. A synthetic oxytocin preparation ( $525 \mathrm{U} / \mathrm{mg}$, Organon B.V., Oss, The Netherlands) was used for iodination and standard curves. The iodination was performed according to Robertson, Roth, Beardwell, Klein, Peterson, and Gordon (1973) using the chloramine-T method. Purification of the reaction mixture was performed using a Sephadex G-25 fine column, which was equilibrated and eluted with $0.25 \%$ acetic acid and human serum albumin $(1.25 \mathrm{mg} / \mathrm{ml})$. OXT was extracted from plasma $(2.0 \mathrm{ml})$ and CSF $(150$ $\mu l)$ with activated Vycor glass powder, using a method similar to that described by Dogterom et al. (1978). The intraassay cofefficient of variation of the OXT RIA was $16.1 \%$ whereas the interassay coefficient of variation amounted to $11.2 \%$.

Arginine-8-vasopressin (AVP) was measured by RIA after cxtraction from plasma $(2.0 \mathrm{ml})$ or CSF $(150 \mu \mathrm{l})$ with activated Vycor glass powder, as described by Dogterom et al. (1978). The antiserum used (in a final dilution of $1: 30,000$ ) was highly specific for AVP; the cross-reactivity with oxytocin being less than $0.1 \%$ and with vasotocin $12.4 \%$.

Neurophysin (NP) was measured by RIA using BN (pII) as standard and labeled antigen (Legros, 1976). Total amount of NP I and NP II was determined.

\section{Experimental Design}

Groups of rats were submitted to a passive avoidance training, and CSF and plasma samples were obtained at different time points during the training of the rats. CSF was withdrawn during the adaptation trial, $20 \mathrm{~min}$ after the learning trial and $3 \mathrm{~min}$ after the onset of the retention session. Blood was collected by decapitation $20 \mathrm{~min}$ after the learning trial and $3 \mathrm{~min}$ after the onset of the retention session. These different time points after the learning and retention trial were chosen because it was considered that the shock applied during the learning trial is a strong aversive stimulus for the rat, while the retention can be regarded as a more weak and vulnerable behavioral stimulus.

For the determination of OXT and AVP in CSF, two samples were pooled, whereas NP was determined in individual samples. To obtain plasma the heparinized polypropylene tubes were centrifuged after collection of trunk blood at $4^{\circ} \mathrm{C}$ for $10 \mathrm{~min}$ at $3000 \mathrm{rpm}$. Plasma and CSF samples were stored at $-20^{\circ} \mathrm{C}$ until tested.

\section{Data Analysis}

The RIA results were calculated on a Hewlett-Packard 104 calculator programmed with a logit curve fitting program. The data were corrected for recovery which was approximately $50 \%$. To determine a possible relationship between avoidance latencies during retention and neuro- 
hypophyseal peptide levels in blood or CSF Spearman's coefficients of rank correlation were calculated. Statistical significance was determined by unpaired Student's $t$ test or analysis of variance (ANOVA) as appropriate.

\section{RESULTS}

Neurohypophyseal Peptide Levels in CSF during Passive

\section{Avoidance Training}

OXT levels in CSF of rats submitted to passive avoidance training did not change during adaptation, acquisition, or retention of the response. During the adaptation session OXT levels in CSF were $64.0 \pm 10.2 \mathrm{pg} /$ $\mathrm{ml}(N=16)$. Twenty minutes after the learning trial the OXT levels ranged from $53.9 \pm 7.7 \mathrm{pg} / \mathrm{ml}$ in the nonshocked group to $65.8 \pm 14.9$ $\mathrm{pg} / \mathrm{ml}$ in the $0.25-\mathrm{mA}$ shocked group (Table 1). Additionally, no difference in OXT levels in CSF obtained from groups of differently shocked animals during the retention session were observed, although marked differences in avoidance latencies were found (Table 2 ). The rank correlation coefficient $\left(R_{s}\right)$ between avoidance latencies and OXT levels in CSF was 0.11 $(N=16)$, indicating that there was no relationship between these two parameters (Fig. 1).

During the adaptation session AVP levels in CSF amounted to 13.3 $\pm 4.8 \mathrm{pg} / \mathrm{ml}$ whereas $20 \mathrm{~min}$ after the learning trial these levels amounted to $10.2 \pm 3.0 \mathrm{pg} / \mathrm{ml}$ (Table 3). Rats that received an EFS of $0.5 \mathrm{~mA}$ during the learning trial showed a diverged pattern of avoidance latencies $24 \mathrm{hr}$ later. One group of animals displayed a maximal avoidance latency of $180 \mathrm{sec}$ (avoiders); another group of rats showed a median avoidance latency of $68 \mathrm{sec}$ (nonavoiders) (Fig. 2). The AVP levels in CSF of the nonavoiders were $20.2 \pm 2.6 \mathrm{pg} / \mathrm{ml}$, whereas the AVP levels in CSF of the avoiders were $23.0 \pm 3.2 \mathrm{pg} / \mathrm{ml}$ (Table 3). No relationship between individual CSF levels of AVP and avoidance latencies was found $\left(\boldsymbol{R}_{s}\right.$ $=0.22 ; N=23$ ).

NP levels after the adaptation trial NP levels were $11.0 \pm 0.8 \mathrm{ng} / \mathrm{ml}$

TABLE 1

Neurohypophyseal Peptide Levels in CSF and Plasma 20 min after Application of Different Shock Intensities (Learning Trial)

\begin{tabular}{lrrrrr}
\hline & \multicolumn{2}{c}{$0.00 \mathrm{~mA}$} & \multicolumn{2}{c}{$0.25 \mathrm{~mA}$} & $0.75 \mathrm{~mA}$ \\
\hline CSF OXT (pg/ml) & $53.9 \pm 7.7(5)$ & $65.8 \pm 14.9$ & $(6)$ & $62.2 \pm 14.0(5)$ \\
CSF NP (ng/ml) & $12.3 \pm 0.7(6)$ & $10.6 \pm 0.5$ & $(7)$ & $11.3 \pm 0.5(6)$ \\
Plasma OXT (pg/ml) & $7.0 \pm 1.8(15)$ & $2.8 \pm 0.5^{*}(14)$ & $4.2 \pm 0.8(16)$ \\
Plasma NP (ng/ml) & $2.2 \pm 0.3(6)$ & $1.9 \pm 0.1$ & $(7)$ & $2.2 \pm 0.2(7)$ \\
\hline
\end{tabular}

Note. Results are expressed as mean \pm SEM. Number of samples is given in parentheses.

${ }^{*} \boldsymbol{P}<0.05,0.25$ versus $0.00 \mathrm{~mA}$. 


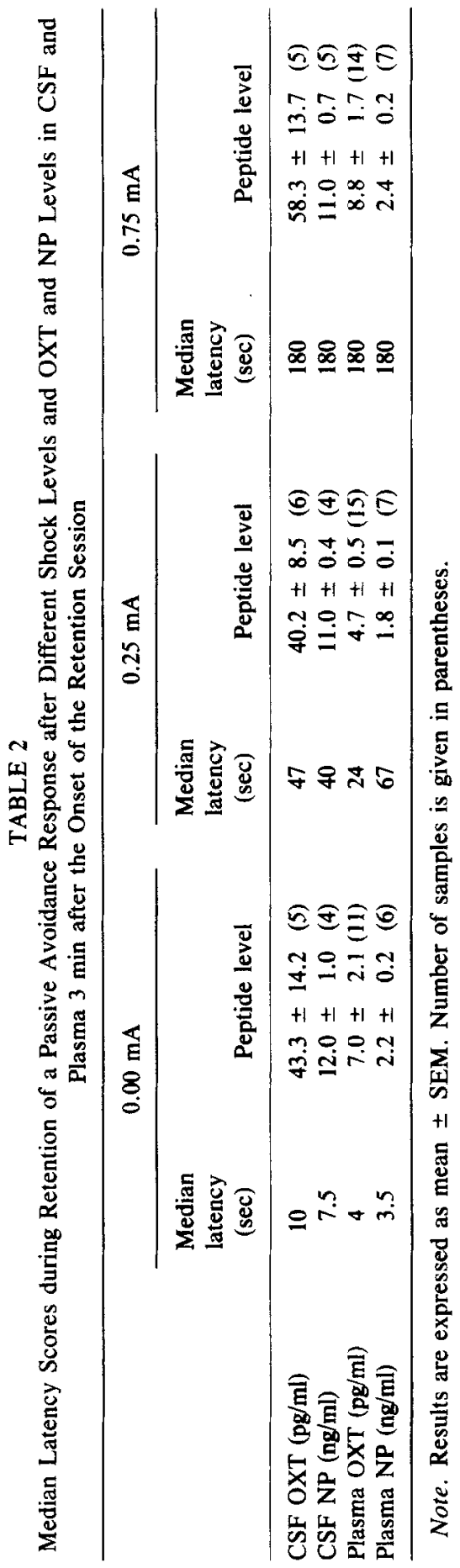




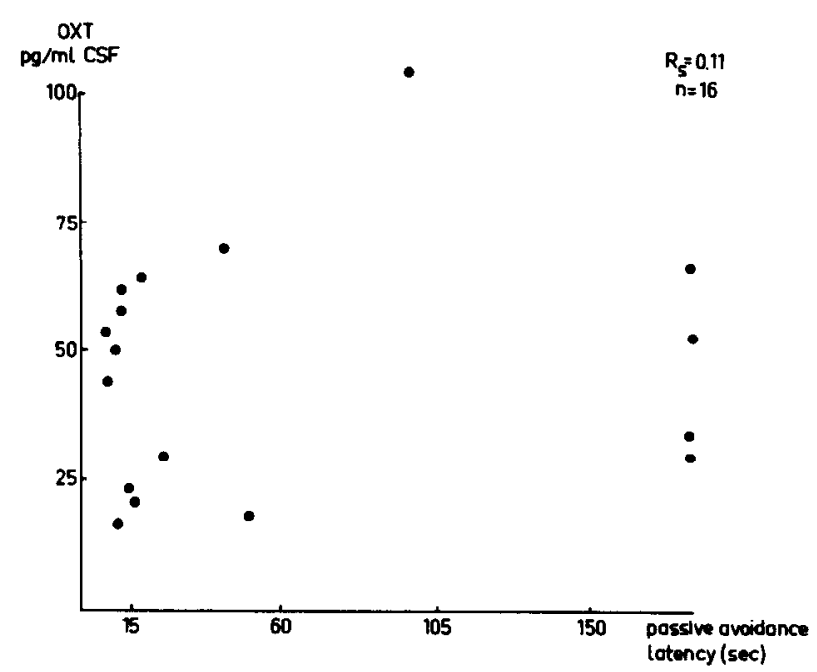

FIG. 1. Relationship between oxytocin levels in CSF and passive avoidance latencies (see text for details). Spearman's coefficient of rank correlations was $0.11(n=16)$.

$(N=18)$ and these levels were not changed $20 \mathrm{~min}$ after the learning trial (Table 1) or $3 \mathrm{~min}$ after the onset of the retention session (Table 2). Further analysis of NP levels in CSF and avoidance latencies showed that there was no relationship between these two parameters $\left(R_{s}=\right.$ $-0.31 ; N=13$ ) (Fig. 3).

Plasma Levels of Neurohypophyseal Peptides during Acquisition and Retention of Passive Avoidance Behavior

The basal level of OXT in plasma of rats prior to behavioral experimentation was $5.5 \pm 0.9 \mathrm{pg} / \mathrm{ml}(N=12)$. Twenty minutes after the learning trial OXT levels in the nonshocked rats amounted to $7.0 \pm 1.8$

TABLE 3

AVP (pg/ml) Levels in CSF and Plasma of Rats during Adaptation, Acquisition, and Retention of Passive Avoidance Behavior

\begin{tabular}{lcccc}
\hline & Adaptation & Learning trial & Retention session & $\begin{array}{c}\text { Median } \\
\text { latency } \\
(\mathrm{sec})\end{array}$ \\
\hline CSF & $13.3 \pm 4.8(7)$ & $10.2 \pm 3.0(7)$ & $\begin{array}{r}20.3 \pm 2.6(n=11)^{*} \\
23.0 \pm 3.2(n=12)\end{array}$ & $\begin{array}{r}68 \\
\text { Plasma }\end{array}$ \\
\hline
\end{tabular}

Note. A current of $0.5 \mathrm{~mA}$ was applied during the learning trial. Results are expressed as mean \pm SEM. Number of samples is given in parentheses.

* Median latency scores during the retention session and AVP levels in CSF are expressed in nonavoiding animals and avoiding animals, respectively. 


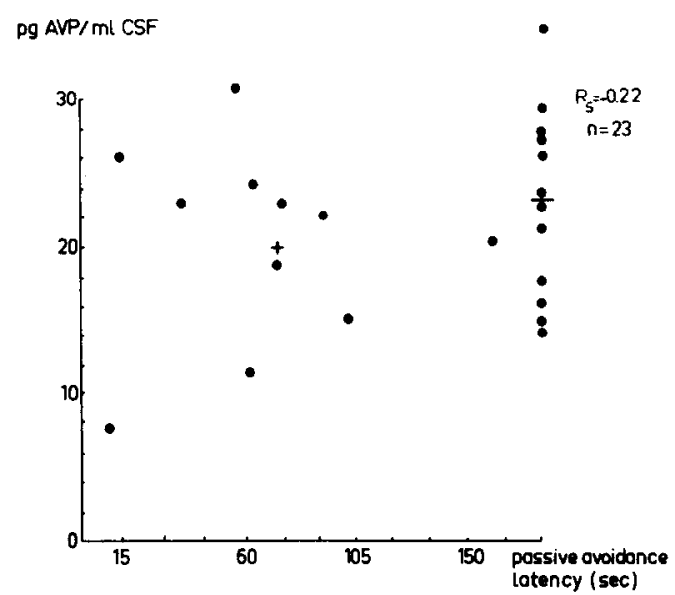

FIG. 2. Relationship between arginine vasopressin levels in CSF and passive avoidance latencies. Rats received an EFS of $0.5 \mathrm{~mA}$ during the learning trial. Median latency of nonavoiders $68 \mathrm{sec}(+)$. Latency of avoiders $>180 \mathrm{sec}(-)$. Nonavoiders: $20.3 \pm 2.6 \mathrm{pg}$ AVP/ml CSF $(n=11)$; avoiders: $23.0 \pm 3.2 \mathrm{pg} \mathrm{AVP} / \mathrm{ml} \operatorname{CSF}(n=12)$.

$\mathrm{pg} / \mathrm{ml}$ (Table 1). In the $0.25-\mathrm{mA}$ shocked group these levels were significantly decreased to $2.8 \pm 0.5 \mathrm{pg} / \mathrm{ml}(F(1,27)=4.8 ; P<0.05)$. In contrast, OXT levels of animals that received a shock intensity of 0.75 $\mathrm{mA}$ during the learning trial were not different from those of the nonshocked group. Whereas the median avoidance latencies during retention varied in the various groups from 3.5 to $\geqslant 180 \mathrm{sec}$, the OXT levels as measured at $3 \mathrm{~min}$ after the onset of the retention session ranged from $7.0 \pm 2.1 \mathrm{pg} / \mathrm{ml}$ in the nonshocked group to $4.7 \pm 0.5 \mathrm{pg} / \mathrm{ml}$ in the $0.25-$

ng NP/ml CSF

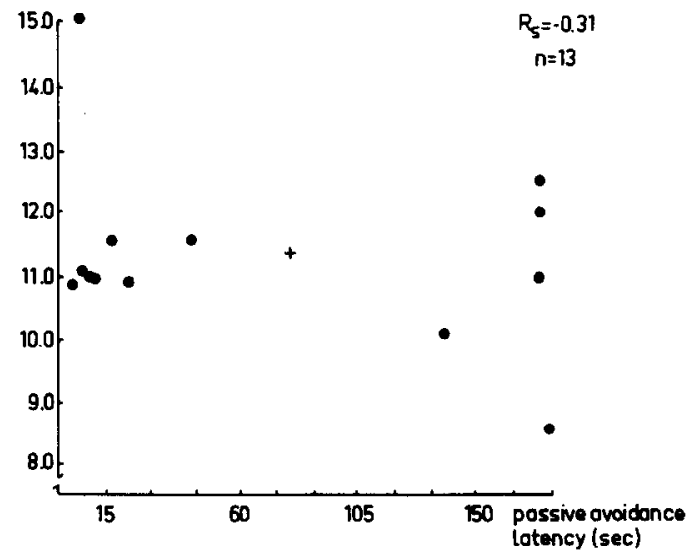

Fig. 3. Relationship between neurophysin levels in CSF and passive avoidance latencies. Spearman's coefficient of rank correlation was $-0.31(n=13)$. 
$\mathrm{mA}$ shocked group up to $8.8 \pm 1.7 \mathrm{pg} / \mathrm{ml}$ in the 0.75 - $\mathrm{mA}$ shocked group (Table 2). No relationship was found between OXT levels in plasma and avoidance latencies $\left(R_{s}=-0.02 ; N=40\right)$.

AVP levels in plasma of rats subjected to an EFS of $0.50 \mathrm{~mA}$ during the learning trial amounted to $2.3 \pm 0.4 \mathrm{pg} / \mathrm{ml}$. These levels were not different from the levels of AVP found during the adaptation trial (Table 3). AVP levels as measured $3 \mathrm{~min}$ after the onset of the retention session were $3.1 \pm 0.5 \mathrm{pg} / \mathrm{ml}$ (Table 3). There was no relationship between avoidance latency and AVP levels in plasma $\left(R_{s}=0.16 ; N=8\right)$.

Submitting rats to various shock intensities did not affect their plasma NP levels as measured $20 \mathrm{~min}$ after the learning trial (Table 1). Moreover, during the retention session no difference between NP levels was found, despite the large differences in avoidance latencies (Table 2). Further analysis of these latter data revealed that there was no relationship between avoidance latencies and NP levels in plasma $\left(R_{s}=0.27\right.$; $N=20$ ).

\section{DISCUSSION}

It is generally assumed that emotional stimuli can affect the release of AVP, OXT, and NP from the neurohypophysis ( $O$ 'Connor and Verney, 1942; Fendler, Rákóczi, and Zibotics, 1966; Pickford, 1969). However, Husain, Manger, Weiss, Hart, and Franz (1976) reported that several noxious stimuli including loud noise and forced exercise did not affect plasma AVP levels. Thompson and De Wied (1973) have reported that the antidiuretic activity of eyeplexus blood in rats increased during a 24hr postshock retention trial of a passive avoidance response. However, using a RIA, changes in AVP levels in peripheral blood and in ventricular CSF could not be demonstrated using various shock intensities during the learning trial, although these different shock intensities resulted in marked differences in avoidance latencies during retention (Van Wimersma Greidanus et al., 1979b). In the present study only one shock level was used during the learning trial and this induced a wide range of avoidance latencies during retention, which were not correlated to vasopressin levels in blood and CSF. Thus, the present results confirm the lack of relationship between AVP levels in peripheral blood or CSF and retention of a passive avoidance response as previously reported. In fact the present data show that generally the levels of AVP, OXT, and of NP in CSF or in plasma of rats did not change during adaptation to or acquisition and retention of a passive avoidance response. Only a slight but significant decrease in plasma OXT levels was observed at $20 \mathrm{~min}$ after the learning trial when a shock intensity of $0.25 \mathrm{~mA}$ was applied. This change in OXT levels did not occur in CSF. The significance of this observed decrease of plasma OXT levels is not clear, more in 
particular since no change was found in the plasma OXT levels of rats submitted to higher shock intensities. Further studies are needed to reveal whether or not this change is of physiological importance.

The absence of any relationship between AVP, OXT, or NP levels in CSF and passive avoidance retention, as shown in the present study, suggests that under the conditions (e.g., time points) used the CSF is not involved in the distribution of neurohypophyseal peptides to their possible sites of behavioral action in the brain. Previous findings presented by Van Wimersma Greidanus et al. (1979b) also support this hypothesis, although in that study CSF was withdrawn from the lateral ventricle and not from the cisterna magna as in the present experiments. This difference in CSF origin may account for the lower levels of AVP in CSF observed in the present experiment as compared to the previous study. Recently CSF AVP levels in both compartments have been compared and indeed the AVP levels in ventricular CSF are higher than those in cisternal CSF (Mens, unpublished observations), although these AVP levels in ventricular CSF were not as high as reported previously.

Extrahypothalamic projections of AVP, OXT, and NP containing neurons from the suprachiasmatic, paraventricular, and supraoptic nuclei to limbic structures such as the amygdala, the septal region, dorsal thalamic nuclei, and other structures, indicate that these neurohypophyseal peptides are distributed within the brain itself (Buijs, 1978; Buijs, Swaab, Dogterom, and Van Leeuwen, 1978; Sofroniew and Weindl, 1978; Vandesande et al., 1975). These peptides may be directly transported from their sites of synthesis to their sites of behavioral action in the brain. Consequently, they may be directly released at these latter sites of action in order to induce their behavioral effect. The observation that behavioral changes induced (reduction of the bioavailable amount of AVP in the brain) by AVP antiserum can be obtained by much smaller amounts upon local application in the dorsal hippocampal or posterior thalamic area than following icv administration further supports this view (Kovács, Buijs, Bohus, and Van Wimersma Greidanus, 1981; Van Wimersma Greidanus, unpublished results). If the local release of neuropeptides of neurohypophyseal origin occurs at these limbic sites of behavioral action transport or distribution of these neuropeptides by means of the CSF is not essential. It may also be that a local release of neuropeptides in restricted regions of the brain is reflected in changes in CSF content of these principles. However, in that case these changes in CSF levels of neuropeptides might probably be too small to be detected. Whether or not a local release of neuropeptides in the brain indeed takes place remains subject for further investigations. Results of such studies may provide conclusive evidence for the physiological significance of endogenous neurohypophyseal peptides in brain function and behavior. 


\section{ACKNOWLEDGMENTS}

The investigations were supported by the Foundation for Medical Research FUNGO which is subsidized by the Netherlands Organization for the Advancement of Pure Research.

Dr. J. J. Legros (Liège, Belgium) is gratefully acknowledged for measuring neurophysin. The technical assistance of Miss A. F. van Dam is very much appreciated.

\section{REFERENCES}

Ader, R., and De Wied, D. (1972). Effects of lysine vasopressin on passive avoidance learning. Psychon. Sci. 29, 46-48.

Ader, R., Weijnen, J. A. W. M., and Moleman, P. (1972). Retention of a passive avoidance response as a function of the intensity and duration of electric shock. Psychon. Sci. 26, $125-129$.

Bohus, B., Kovacs, G. L., and De Wied, D. (1978a). Oxytocin, vasopressin and memory: Opposite effects on consolidation and retrieval process. Brain Res. 157, 414-417.

Bohus, B., Urban, I., Van Wimersma Greidanus, Tj. B., and De Wied, D. (1978b). Opposite effects of oxytocin and vasopressin on avoidance behavior and hippocampal theta rhythm in the rat. Neuropharmacology 17, 239-247.

Bouman, H. J., and Van Wimersma Greidanus, Tj. B. (1979). A rapid and simple cannulation technique for repeated sampling of cerebrospinal fluid in freely moving rats. Brain Res. Bull. 4, 575-577.

Brownfield, M. S., and Kozlowski, G. P. (1977). The hypothalamo-choroid tract. 1. Immunohistochemical demonstration of neurophysin pathways to telencephalic choroid plexuses and cerebrospinal fluid. Cell. Tissue Res. 178, 111-127.

Buijs, R. M. (1978). Intra- and extrahypothalamic vasopressin and oxytocin pathways in the rat. Cell. Tissue Res. 192, 423-435.

Buijs, R. M., Swaab, D. F., Dogterom, J., and Van Leeuwen, F. W. (1978). Intra- and extrahypothalamic vasopressin and oxytocin pathways in the rat. Cell. Tissue Res. 186, 423-433.

De Wied, D. (1976). Behavioral effects of intraventricularly administered vasopressin and vasopressin fragments. Life Sci. 19, 685-690.

Dogterom, J., Van Wimersma Greidanus, Tj. B., and De Wied, D. (1978). Vasopressin in cerebrospinal fluid and plasma of man, dog and rat. Amer. J. Physiol. 234, E463-E467.

Fendler, K., Rákóczi, I., and Zibotics, H. (1966). Effect of daily electroshock treatment on neurohypophyseal hormone content in the rat. Acta Physiol. Acad. Sri. Hung. 29, 41-46.

Goldsmith, P. C., and Zimmerman, E. A. (1975). Ultrastructural localization of neurophysin and vasopressin in the rat median eminence. Abstract Progr. 57th Ann. Meet. Endocrine Soc., A377.

Husain, M. K., Manger, W. M., Weiss, R., Hart, C., and Franz, A. G. (1976). Vasopressin release in the rat after manual restraint: An effect of abdominal compression and not of stress. Abstract Vth International Congress of Endocrinology, Hamburg, July 18-24, No. 481.

Kovács, G. L., Buijs, R. M., Bohus, B., and Van Wimersma Greidanus, Tj. B. (1982). Microinjection of arginine-vasopressin antiserum into the dorsal hippocampus attenuates passive avoidance behavior in rats. Physiol. Behav. 28, 45-48.

Legros, J. J. (1976). In Les Neurophysines Recherches Methodologiques, Expérimentales et Cliniques, pp. 1-265. Mason, Paris.

O'Connor, W. J., and Verney, E. B. (1942). The effect of removal of the posterior lobe of the pituitary on the inhibition of water diuresis by emotional stress. Quart. J. Exp. Physiol. 31, 393-408. 
Pickford, M. (1969). Neurohypophysis-antidiuretic (vasopressor) and oxytocic hormones. In W. Haymaker, E. Anderson, and W. J. H. Nauta (Eds.), The Hypothalamus, pp. 463-505. Thomas, Springfield, Ill.

Rigter, H., Van Riezen, H., and De Wied, D. (1974). The effects of ACTH- and vasopressinanalogues on $\mathrm{CO}_{2}$-induced retrograde amnesia in rats. Physiol. Behav. 13, 381-388.

Robertson, G. L., Roth, J., Beardwell, C., Klein, Z. A., Peterson, M. J., and Gordon, $\mathrm{Ph}$. (1973). Radioimmunoassay of vasopressin. In S. A. Berson and R. S. Yalow (Eds.), Methods in Investigative and Diagnostic Endocrinology, Vol. 2A, Part II, pp. 656-667. North-Holland, New York/Amsterdam.

Sachs, H., Fawcett, P., Takabatake, Y., and Portanova, K. (1969). Biosynthesis and release of vasopressin and neurophysin. Recent Progr. Horm. Res. 25, 447-491.

Sofroniew, M. V., and Weindl, A. (1978). Extrahypothalamic neurophysin containing perikarya, fiber pathways and fiber clusters in the rat brain. Endocrinology 102, 334-337.

Sokol, H. W., Zimmerman, E. A., Sawyer, W. H., and Robinson, A. G. (1976). The hypothalamic-neurohypophyseal system of the rat: Localization and quantitation of neurophysin by light microscopic immunocytochemistry in normal rats and in Brattleboro rats deficient in vasopressin and a neurophysin. Endocrinology 98, 1176-1188.

Swaab, D. F., and Pool, C. W. (1975). Specificity of oxytocin and vasopressin immunofluorescence. J. Endocrinol. 66, 263-272.

Swanson, L. W., and Cowan, W. M. (1975). The efferent connections of the suprachiasmatic nucleus of the hypothalamus. J. Comp. Neurol. 160, 1-12.

Thompson, E. A., and De Wied, D. (1973). The relationship between the antidiuretic activity of rat eye plexus blood and passive avoidance behavior. Physiol. Behav. 11, $377-380$.

Vandesande, F., Dierickx, K., and De Mey, J. (1975). Identification of the vasopressinneurophysin producing neurons of the rat suprachiasmatic nuclei. Cell. Tissue Res. 156, 377-380.

Van Wimersma Greidanus, Tj. B. (1978). Behavioral changes of rats after neutralization of central available neuropeptides by administration of specific antisera. In P. J. Gaillard and H. H. Boer (Eds.), Comparative Endocrinology, pp. 192-193. Elsevier/ North-Holland, New York/Amsterdam.

Van Wimersma Greidanus, Tj. B., and De Wied, D. (1976). Modulation of passive avoidance behavior of rats by intracerebroventricular administration of antivasopressin serum. Behav. Biol. 18, 325-333.

Van Wimersma Greidanus, Tj. B., Dogterom, J., and De Wied, D. (1975). Intraventricular administration of anti-vasopressin serum inhibits memory consolidation in rats. Life Sci. 16, 637-644.

Van Wimersma Greidanus, Tj. B., Croiset, G., Bakker, E. A. D., and Bouman, H. J. (1979a). Amygdaloid lesions block the effect of neuropeptides (vasopressin, $\mathrm{ACTH}_{4-10}$ ) on avoidance behavior. Physiol. Behav. 22, 291-295.

Van Wimersma Greidanus, Tj. B., Croiset, G., Goedemans, H., and Dogterom, J. (1979b). Vasopressin levels in peripheral blood and in cerebrospinal fluid during passive and active avoidance behavior in rats. Horm. Behav. 12, 103-111.

Wittkowski, W. (1968). Elektronenmikroskopische Studien zur intraventrikulär Neurosekretion in den Recessus infundibularis der Maus. Z. Zellforsch. 92, 207-216. 